\title{
Combined effects of drought and the fungicide tebuconazole on aquatic leaf litter decomposition
}

\author{
Stéphane Pesce ${ }^{1}$, Olfa Zoghlami ${ }^{1}$, Christelle Margoum ${ }^{1}$, Joan Artigas ${ }^{2,3}$, Arnaud \\ Chaumot $^{1}$, Arnaud Foulquier ${ }^{1,4}$
}

1. Irstea, UR MALY, Centre de Lyon-Villeurbanne, 5 rue de la Doua, CS70077, 69626 Villeurbanne Cedex, France

2. Laboratoire Microorganismes: Génome et Environnement, Clermont Université, Université Blaise Pascal, Clermont-Ferrand, France

3. CNRS, UMR 6023, LMGE, Aubiere, France

4. Laboratoire d'Écologie Alpine, UMR 5553 CNRS, Université Grenoble Alpes, BP 53, 38041 Grenoble Cedex 9, France

Corresponding author : Stéphane Pesce - stephane.pesce@irstea.fr

\section{Highlights}

- The combined effects of drought and the fungicide tebuconazole on aquatic leaf litter decomposition (LLD) were assessed.

- TBZ applied alone had no significant effect on LLD.

- Drought strongly impacted the microbial LLD process and led to cascading effects on Gammarus feeding.

- Structural and functional effects increased when drought and TBZ were applied simultaneously.

\section{$\underline{\text { Abstract }}$}

Loss of biodiversity and altered ecosystem functioning are driven by the cumulative effects of multiple natural and anthropogenic stressors affecting both quantity and quality of water resources. Here we performed a 40-day laboratory microcosm experiment to assess the individual and combined effects of drought and the model fungicide tebuconazole (TBZ) on leaf litter decomposition (LLD), a fundamental biogeochemical process in freshwater ecosystems. Starting out from a worst-case scenario perspective, leaf-associated microbial communities were exposed to severe drought conditions (four 5-day drought periods alternated with 4-day immersion periods) and/or a chronic exposure to TBZ (nominal concentration of $20 \mu \mathrm{g} L-1$ ). We assessed the direct effects of drought and fungicide on the structure (biomass, diversity) and activity (extracellular enzymatic potential) of fungal and bacterial assemblages colonizing leaves. We also investigated indirect effects on the feeding rates of the amphipod Gammarus fossarum on leaves previously exposed to drought and/or TBZ contamination. Results indicate a stronger effect of drought stress than fungicide contamination under the experimental conditions applied. Indeed, the drought stress strongly impacted microbial community structure and activities, inhibiting the LLD process and leading to cascading effects on macroinvertebrate feeding. However, despite the lack of significant effect of TBZ applied alone, the effects of drought on microbial functions (i.e., decrease in LLD and in enzymatic activities) and on Gammarus feeding rates were more pronounced 
when drought and TBZ stresses were applied together. In a perspective of ecological risk assessment and ecosystem management for sustainability, these findings stress the need for deeper insight into how multiple stressors can affect the functioning of aquatic ecosystems and associated services.

\section{Keywords}

Microbial communities - Microbial ecotoxicology - Multistress - Shredders - Aquatic food web - Biodiversity-ecosystem function relationship

\section{Introduction}

Among ecological processes, the decomposition of allochthonous organic matter in the form of leaves is central to the functioning of lotic ecosystems and their associated services (Webster and Meyer, 1997). Leaf litter decomposition (LLD) is mediated by the combined action of microbial and invertebrate communities and contributes to the recycling of organic carbon and nutrients originating from the riparian vegetation (Graça, 2001 and Romaní et al., 2006). Through their extracellular enzymatic activities, fungi, particularly aquatic hyphomycetes, and bacteria drive the first steps of LLD and regulate the transfer of matter and energy between particulate organic matter and upper trophic levels through conversion into microbial biomass (Baldy et al., 1995 and Romaní et al., 2006). Moreover, microorganisms stimulate leaf consumption by macroinvertebrate shredders through their enzymatic activities and subsequent softening of leaf tissues, and by increasing the nutritional quality of leaf (Suberkropp et al., 1983). Due to its fundamental role in ecosystem metabolism, LLD is a relevant tool to assess the functional integrity of streams (Gessner and Chauvet, 2002 and Zubrod et al., 2015a).

Among other stressors, the occurrence, frequency and severity of drying events are increasing in rivers worldwide, leading to an increase in number and length of intermittent rivers (Datry et al., 2014). Drought events can profoundly affect the LLD process by reducing decomposition activity during dry phases (Langhans and Tockner, 2006 and Corti et al., 2011), with legacy effects persisting in invertebrate communities for several months after flow has resumed (Datry et al., 2011). Such effects are partly explained by changes in abiotic processes driving LLD, including leaching of soluble compounds and physical abrasion (Bärlocher, 1992). However, the most critical aspect of emersion periods lies in the physiological stress and spatial confinement (i.e., humid sediment patches and leaf litter refuges (Amalfitano et al., 2007 and Ylla et al., 2010)) imposed on aquatic organisms that results in marked changes in the community structure and activity dynamics of microbial decomposers and invertebrate detritivores (Larned et al., 2007, Datry, 2012 and Foulquier et al., 2015). Moreover, terrestrial invertebrates colonizing the river during droughts (Adis and Junk, 2002 and Corti and Datry, 2016) can eventually outcompete strictly aquatic organisms and modify the decomposition of leaf litter accumulated in dry river beds. Increasing emersion duration thus decreases LLD rates via a reduction in microbial biomass and activity, and in shredder densities or feeding activities (Langhans and Tockner, 2006, Datry et al., 2011 and Foulquier et al., 2015).

Chemical contamination also counts as a widespread stressor in freshwater ecosystems (Segner et al., 2014). This is especially the case in rivers draining agricultural areas, where the diffuse pollution of pesticides to freshwaters can reduce the LLD process (Piscart et al., 2011 and Rasmussen et al., 2012a). Recent studies showed that the fungicide tebuconazole (TBZ), which belongs to the intensively used class of azoles (Richardson and Ternes, 2009), can significantly inhibit LLD through a reduction in fungal and bacterial biomass on leaves, changes in microbial community structure, and a decrease in microbial extracellular enzyme activities responsible for cellulose and hemicellulose degradation (Bundschuh et al., 2011, Zubrod et al., 2011, Zubrod et al., 2015a and Artigas et al., 2012). The mode of action of TBZ relies on the inhibition of the biosynthesis of ergosterol, a sterol essential for the functioning 
of fungal cells due to its role in cell membrane permeability and fluidity. The reported impacts of TBZ on microbial communities can also induce indirect effects on leaf shredding invertebrates due to the reduction in palatability and nutritional quality of leaf resources (Bundschuh et al., 2011 and Zubrod et al., 2011). TBZ can also have direct sublethal effects on shredders, especially inhibition of feeding activity (Zubrod et al., 2014). Fungicides may thus potentially have cascading impacts on aquatic food webs, and strongly influence the organic matter dynamics in river ecosystems.

Against this background, there is now strong evidence that drought and fungicide contamination can affect LLD through both direct and indirect effects on decomposer communities. However, the combined effects of these two stressors on aquatic ecosystem functioning remain to be determined. Current approaches to hazard and risk assessment mainly focus on single stressor effects, yet there is a pressing need for better knowledge on how multiple stressors can affect aquatic biota and functioning (Segner et al., 2014). Here we performed a 40-day laboratory microcosm experiment to assess the individual and combined effects of drought and fungicide (TBZ) on leaf-associated microbial (fungi and bacteria) communities responsible for LLD, including subsequent modification of leaf palatability for invertebrate shredders. Starting out from a worst-case scenario perspective, the microbial communities were exposed to severe drought conditions (four 5-day drought periods preceded and followed by 4-day immersion periods) and/or a chronic exposure to TBZ (nominal concentration of $20 \mu \mathrm{g} \mathrm{L}-1$ ). We assessed the direct effects of drought and fungicide on the structure (biomass, diversity) and activity (LLD, extracellular enzyme activity) of fungal and bacterial assemblages colonizing leaves. We also investigated indirect effects on the feeding rates of the invertebrate crustacean Gammarus fossarum (a shredder amphipod which represents the dominant macroinvertebrate species, in terms of biomass, in many lotic ecosystems; Macneil et al., 1997) by using leaves previously exposed to drought and/or TBZ contamination.

We hypothesized that each stress applied individually would impair microbial community diversity and activity by modifying community composition, reducing microbial biomasses and enzymatic activities, and consequently decreasing LLD rates. We also addressed the question of combined effects. Ergosterol was recently found to be a key membrane component involved in the resistance of fungi to air-drying through its role of antioxidant and mechanical stabilizer in the plasma membrane (Dupont et al., 2012). The inhibition of fungal ergosterol biosynthesis under TBZ exposure could thus increase the stress induced by drying events on fungal communities. Conversely, the physiological stress imposed on microbial communities during drying events could weaken microorganisms and increase their sensitivity toward TBZ. Accordingly, we made the hypothesis of a synergistic effect of the two stressors on LLD. We expected that these direct effects would indirectly affect G. fossarum feeding activity, either by reducing leaf consumption rates due to a decrease in palatability or, on the contrary, by triggering an increase in feeding rates to compensate for the decrease in leaf nutritional quality (mechanism of compensatory feeding ( Agatz et al., 2014).

\section{Materials and methods}

\subsection{Microbial colonization of leaves}

Recently-fallen leaves of Alnus glutinosa were collected in November 2013, transported to the lab and allowed to dry at room temperature. The leaves were rehydrated, cut into 1 and 2 $\mathrm{cm}$-diameter circles, and oven-dried for $48 \mathrm{~h}$ at $70^{\circ} \mathrm{C}$. These leaf disks were weighed and respectively placed in small litter bags $(\mathrm{I} \times \mathrm{w}=9 \times 5.5 \mathrm{~cm})$ containing 20 leaf discs $(1 \mathrm{~cm}$ in diameter) and large litter bags $(\mathrm{I} \times \mathrm{w}=9 \times 12 \mathrm{~cm})$ containing 12 leaf disks $(2 \mathrm{~cm}$ in diameter). Bags were placed in fine-meshed nylon bags $(0.25 \mathrm{~mm})$ to prevent invertebrate colonization and immersed for one week (3-10 March, 2014) in the upstream section of the Ardières River (Beaujolais vineyard area, Eastern France) draining a grassland/forest area to allow microbial colonization prior to the microcosm experiment. Colonized leaves were collected and transported to the lab, and used for the subsequent microcosm experiments. 


\subsection{Experimental design}

The experiment was performed in glass indoor channels (Length $\times$ Width $\times$ Height $=83 \mathrm{~cm} \times$ $11 \mathrm{~cm} \times 10 \mathrm{~cm}$ ) simulating four different conditions (Fig. 1): (i) "Ic" (immersed control), where leaves were permanently immersed (40 days) without TBZ exposure, (ii) "Itbz' (immersed TBZ), where leaves were permanently immersed with TBZ exposure (nominal concentration of $20 \mu \mathrm{g} \mathrm{L-1}$ ), (iii) 'Dc' (dried control), where leaves were temporarily immersed (4 45 days) without TBZ exposure, and (iv) "Dtbz" (dried TBZ), where leaves were temporarily immersed with TBZ exposure $(4 \times 5$ days, nominal concentration of $20 \mu \mathrm{g} \mathrm{L}-1)$. Each treatment was replicated in three independent channels, giving 12 channels in total. Each channel was connected to a $20 \mathrm{~L}$ glass tank (i.e., one independent tank per channel) through an aquarium pump (NEWA MJ 750) for water recirculation with a flow velocity of $1.5 \mathrm{~L}$ min-1.

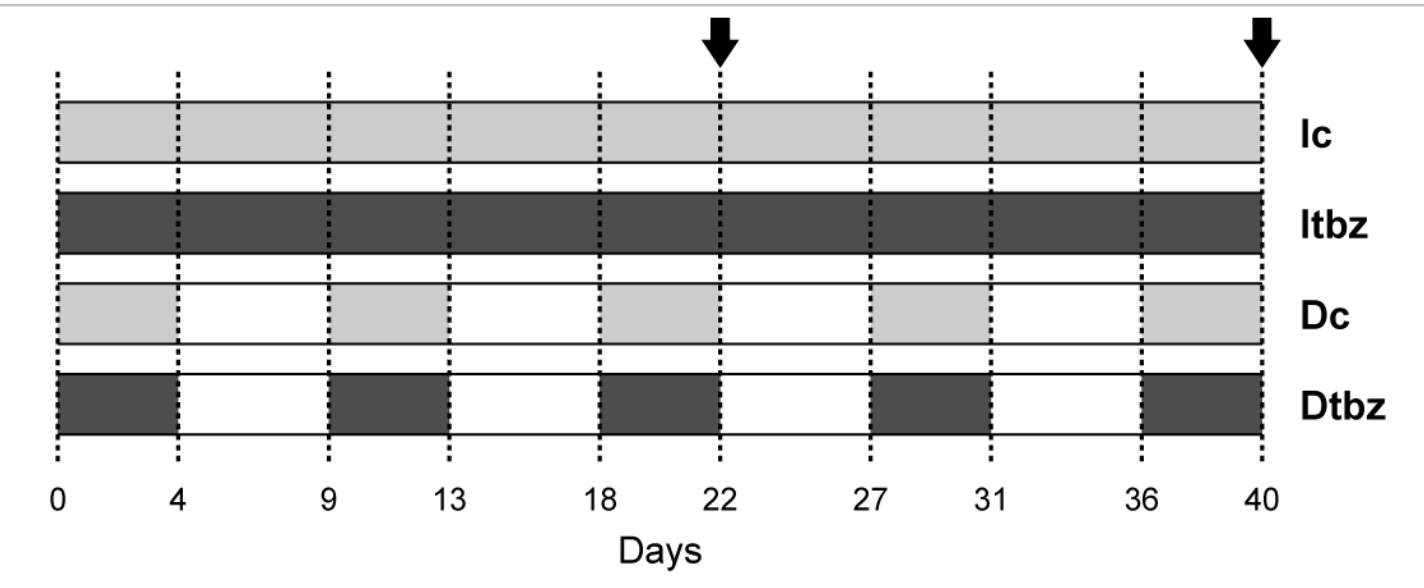

Fig. 1. Microcosm experimental design. "Immersed control" (IC) and "Immersed tebuconazole" (Itbz) microcosms were permanently filled with uncontaminated water (light grey boxes) and TBZ-contaminated water (dark grey boxes), respectively. "Drought control" (Dc) and "Drought tebuconazole" (Dtbz) microcosms were subjected to four 5-day drought periods (white boxes). Dotted lines and arrows respectively indicate water renewal/removal and litter bag sampling dates. Each treatment was triplicated.

The study was led from March 10 to April 20,2014 under controlled temperature $\left(19.9^{\circ} \mathrm{C} \pm\right.$ $0.1)$ and light ( $14 \mathrm{~h} / 10 \mathrm{~h}$ light/dark cycle) conditions. Each independent channel was filled with $5 \mathrm{~L}$ recirculating water. The water was drilled groundwater stored in two $150 \mathrm{~L}$ glass tanks and homogenized using recirculating pumps before being used to fill each independent $20 \mathrm{~L}$ glass tank at each water renewal (every four-five days). The two $150 \mathrm{~L}$ tanks were totally emptied and refilled at each water renewal. One tank was contaminated by TBZ (Sigma-Aldrich, Germany; stock solution: $10 \mathrm{mg} \mathrm{L}-1$ in water) at a nominal concentration of $20 \mu \mathrm{g} \mathrm{L}-1$ and used to fill the contaminated microcosms (Itbz and Dtbz). The second tank only contained uncontaminated drilled water to fill the uncontaminated microcosms (Ic and Dc). Water renewals ensured constant TBZ contamination levels and prevented nutrient limitation for microbial communities. Drought conditions (Dc and Dtbz treatments) were achieved by rapid and total water removals and consisted in four 5-day drought periods preceded and followed by 4-day immersion periods. The frequency of drying events was chosen based on previous studies indicating a predominant effect of drying duration over drying frequency on leaf litter decomposition and associated biotic communities (Langhans and Tockner, 2006 and Foulquier et al., 2015). The cumulative duration of drying was set to $50 \%$ of duration of the study and the drying frequency was chosen to achieve a compromise between environmental realism and technical feasibility in terms of numbers of water renewals. The chosen frequency of drying events could be seen in the context of rivers experiencing strong flow regulation or daily peak hydropower effects with drying events occurring rapidly during low-flow periods (Moog, 1993 and Jones, 2014) on a daily or weekly basis (Fette et al., 2007). 
Each channel was deployed with 13 small litter bags and 8 large litter bags. Litter bag collections ( 5 small bags and 4 large bags) were performed at days 22 and 40 . Sampling times were chosen to detect transitional effects that could lead to differences in functional responses of decomposers among early and more advanced stages of decomposition.

\subsection{Water analyses}

Physical-chemical parameters and dissolved TBZ concentrations were measured before each water renewal in all of the microcosms and in the two tanks used to fill the microcosms. Water temperature, dissolved oxygen, conductivity and $\mathrm{pH}$ were measured using portable meters (WTW, Germany). Standard operating procedures were followed to determine the concentrations of orthophosphates (PO43-; NF EN ISO 6878), nitrates (NO3-; NF EN ISO 10304), nitrites (NO2-; NF EN 26777), ammonium (NH4+; NF T 90-015-2) and dissolved organic carbon (DOC; NF EN 1484). For all parameters measured, the physical-chemical characteristics of the drilled groundwater used to fill the microcosms remained stable throughout the entire experiment without significant difference between the two tanks (i.e., uncontaminated and contaminated tank water; data not shown).

Dissolved TBZ concentrations were determined by direct injection of $20 \mu \mathrm{L}$ of water samples previously filtered in a $0.2 \mu \mathrm{m}$ 25-mm-diameter polyester filter (MACHEREY-NAGEL) into an Ultra-High-Performance Liquid Chromatography (UHPLC) system (Shimadzu Nexera (B) coupled to a triple quadrupole mass spectrometer (API 4000, LC/MS/MS system, AB Sciex). Limit of quantification of TBZ was $0.2 \mu \mathrm{g} \mathrm{L}-1$.

\subsection{Microbial biomass}

Fungal biomass was estimated by ergosterol analysis following the protocol previously described in Gessner and Schmitt (1996). Briefly, lipids were extracted from previously frozen and lyophilized leaf discs ( $1 \mathrm{~cm}$ diameter; 15 per sample). Ergosterol was then separated and concentrated before being analyzed by high-performance liquid chromatography (HPLC; Waters, USA). Ergosterol concentration was converted into fungal carbon using the conversion factors proposed by Gessner and Chauvet (1993) and Baldy and Gessner (1997).

Bacterial biomass was estimated from bacterial densities using a FACS Calibur flow cytometry system (Becton Dickinson Biosciences) and following the protocol of Borrel et al. (2012). For each treatment and sampling date, one leaf disc (1 cm diameter) was conserved in $1 \mathrm{~mL}$ of TE buffer (10 mM Tris, $1 \mathrm{mM}$ EDTA) and $1 \mathrm{~mL}$ of paraformaldehyde (2\%, final concentration) and stored at $-20^{\circ} \mathrm{C}$. Bacterial cells were detached after 30 min incubation in $200 \mu \mathrm{L}$ of $10 \mathrm{mM}$ sodium pyrophosphate under agitation (150 rpm), followed by two sonication steps of $30+30 \mathrm{~s}$. The bacterial suspension was then centrifuged (1 min, $800 \times$ $\mathrm{g}$ ), diluted two-fold with $0.2 \mu \mathrm{m}$-filtered TE buffer, and stained with SYBR Green I $10 \times$ (Molecular Probes, OR, USA) for $15 \mathrm{~min}$ in the dark at room temperature. The data was analyzed using CELLQuest software (BD Biosciences). Cellular density was converted to bacterial biomass using the conversion factors of Bratbak and Dundas (1984) as reference.

\subsection{Microbial community structure}

Automated Ribosomal Intergenic Spacer Analysis (ARISA) was performed as described in Artigas et al. (2012) to fingerprint fungal and bacterial community structure. Microbial DNA was extracted from 4 leaf discs (1 cm diameter) using the FastDNA SPIN kit for soil (MP Biomedicals) according to the manufacturer's instructions. Fungal community structure was characterized using the length polymorphism of the ITS1-5.8S-ITS2 region, and bacterial community structure was determined by amplification of the 16S-23S intergenic spacer region from the bacterial rRNA operon. PCR conditions for bacteria and fungi were as described in Artigas et al. (2012). 
Amplified fragments corresponding to operational taxonomic units (OTUs) were separated and quantified by capillary electrophoresis on an Agilent 2100 Bioanalyzer using a DNA 1000 kit (Agilent Technologies) following the manufacturer's instructions. ARISA profiles were analyzed using GelCompar II version 4.6 software (Applied Maths) to construct two matrices based on fungal and bacterial OTU abundances, respectively. The Hellinger transformation was applied to the OTU abundance matrices in two steps. First, OTU relative abundance within a sample was calculated by dividing the fluorescence intensity of an individual peak by the total intensity of the electrophoretic profile (sum of the intensity of all peaks). This step allows correcting for possible run to run variability in fluorescence signal that may arise during capillary electrophoresis (Yannarell et al., 2011). Data were then square-root transformed to minimize the influence of dominant OTUs on the sample ordination. Fungal and bacterial community distance matrices were then calculated between all pairs of samples using the Bray-Curtis dissimilarity index.

\subsection{Taxonomic composition of fungal communities}

The taxonomic composition of the aquatic hyphomycete communities present on leaves was characterized by microscopic identification of conidia produced after sporulation of 10 leaf discs (1 cm diameter). Hyphomycete sporulation was achieved by incubating leaves in 100 $\mathrm{mL}$ of filtered $(0.7 \mu \mathrm{m})$ drilled water for $48 \mathrm{~h}$ at $10^{\circ} \mathrm{C}$ under a continuous oxygen flow (Gessner and Chauvet, 1994). The resulting suspensions ( $80 \mathrm{~mL}$ ) were mixed with $500 \mu \mathrm{L}$ of Triton-X100 for 10 min with stirring in order to disaggregate thick amounts of conidia, and finally fixed with formalin ( $2 \%$, final concentration). Conidia suspensions were then filtered through $5 \mu \mathrm{m}$ cellulose nitrate filters (Whatmann, Germany) and stained with $0.1 \%$ Trypan blue in $60 \%$ lactic acid. Conidia counting and identification was performed on a Nikon eclipse $80 \mathrm{i} B$ microscope (Nikon Instruments) at $40 \times$ or $100 \times$ magnification. Conidia were identified using the Ingold (1975) guide for aquatic and water-borne hyphomycetes and recent nomenclatures.

\subsection{Leaf mass loss}

The decomposition of Alnus leaves was evaluated as leaf mass loss during the experiment. At each sampling time, 20 discs (1 cm diameter) weighed at the start of the experiment were taken from each treatment, brought to oven dry mass (DM, $70{ }^{\circ} \mathrm{C}$ for $48 \mathrm{~h}$ ), then weighed. Time-course changes in DM were expressed as \% mass remaining relative to initial leaf DM.

\subsection{Extracellular enzymatic activities}

Microbial enzymatic potential was estimated from measurements of cellobiohydrolase (EC 3.2.1.91) and $\beta$-glucosidase (EC 3.2.1.21) activities using a fluorometric method described in Artigas et al. (2012). Briefly, one leaf disk of each microcosm was incubated with $2 \mathrm{~mL}$ of the specific methylumbelliferyl (MUF) substrate analog for each enzyme, at the previouslydetermined saturating concentration. After $1 \mathrm{~h}$ of incubation in the dark under agitation at 20 ${ }^{\circ} \mathrm{C}, 0.3 \mathrm{~mL}$ glycine buffer ( $\left.\mathrm{pH} 10.4\right)$ was added to stop the enzyme reaction and reach maximum MUF fluorescence, which was measured on a Biotek synergy HT fluorometer at 360/460 nm excitation/emission.

\subsection{Feeding rates of Gammarus fossarum}

Leaf discs conditioned by microbial communities in the microcosms were used to measure the indirect effects of drought and TBZ on rate of litter consumption by G. fossarum. Gammarids were collected from a reference site of the Bourbre River (France; Coulaud et al., 2011) three weeks before feeding assays (two campaigns) to allow acclimatization in laboratory conditions (drilled groundwater, water temperature $12^{\circ} \mathrm{C}$, constant oxygenation, conductivity $\sim 500 \mu \mathrm{S} \mathrm{cm}-1,16 / 8$-h light/dark photoperiod, ad libitum feeding with Alnus leaves). At each sampling time, 540 male $\mathrm{G}$. fossarum of homogenous body size (9.9 [ \pm 0.7$]$ $\mathrm{mm}$ and $10.0[ \pm 0.1] \mathrm{mm}$ at Day 22 and Day 40 feeding assays, respectively) were sorted to avoid any sex or size effect on the studied responses (Coulaud et al., 2011). For each treatment, three independent replicates were carried out in plastic microcosms. Each 
microcosm contained $500 \mathrm{~mL}$ of oxygenated water held at a temperature of $11.4( \pm 0.4){ }^{\circ} \mathrm{C}$, $12 \mathrm{G}$. fossarum and 7 leaf discs (2 cm diameter). For each treatment, we ran an additional microcosm containing 7 leaf discs without $G$. fossarum for use as controls to estimate leaf mass loss unrelated to gammarid consumption. During the feeding assays (4 days), water renewal and dead gammarid counts were monitored daily. Only low mortality was observed during feeding assays (less than $1 \%$ in total at Day 22 and less than $2 \%$ in total at Day 40 ), thus never exceeding 1 dead individual per replicate (for a total of 12 individuals per replicate). Dead individuals were removed as soon as they were detected (all dead individuals were retrieved thus indicating that they had not been eaten by other individuals). At the end of the assay, the remaining leaf discs were numerically scanned and the disc surfaces were measured using SigmaScan ${ }^{\circledR}$ Pro v5.0 imaging software (Systat Software). The results were expressed in $\mathrm{mm} 2$ of leaf consumed by $\mathrm{G}$. fossarum per day (see Coulaud et al., 2011 for details). Feeding rates were also expressed in terms of ingested fungal $\mathrm{C}$ (mg Fungal C Gammarus-1 Day-1) using the measurements of fungal $\mathrm{C}$ on leaves (mg Fungal $\mathrm{C}$ $\mathrm{mm}-2$ leaf).

\subsection{Statistical analyses}

Statistical analyses were conducted on data obtained at Day 22 and Day 40. A three-way repeated-measures analysis of variance (ANOVA) was performed to test the effects of drought, fungicide and time on water physical-chemical characteristics, litter mass loss, microbial biomass and activities, and Gammarus feeding rate. ANOVAs were conducted using the "Ime" function from the nlme package ( Pinheiro et al., 2015) in R version 3.1.1. When a significant effect was detected, post-hoc comparisons of means were conducted with a Tukey's test using the "Ismeans" function from the Ismeans package ( Lenth and Hervé, 2015). Whenever necessary, data were $\log 10(x)$-transformed before statistical analysis to satisfy the assumptions of normality and homogeneity of variance. Patterns in fungal (ARISA and taxonomic analysis) and bacterial (ARISA) community structure at Day 22 and Day 40 were visualized using non-metric multidimensional scaling (NMDS) based on Bray-Curtis dissimilarity matrices. NMDS were performed using the vegan package ( Oksanen et al., 2015). The significance of differences in fungal and bacterial community structure among drought and fungicide conditions and among sampling dates was tested using a three-way non-parametric multivariate ANOVA (PERMANOVA) and post-hoc comparisons implemented in the PERMANOVA6 software (Anderson, 2001 and Anderson, 2005).

\section{Results}

\subsection{Physical-chemical parameters}

Mean values of the physical and chemical variables measured in the microcosms before each water renewal are reported in Table 1. Based on data obtained at Day 22 and Day 40, ANOVA indicated that DOC concentrations were significantly higher in drought than in immersed microcosms and significantly higher at Day 40 than at Day 22 (Table 2). Conductivity decreased significantly between Day 22 and Day 40 in all microcosms (post-hoc test, $p$-value $<0.0001$ ) and was significantly higher in drought than in immersed microcosms whatever the date considered (post-hoc test, $p$-value < 0.0004). ANOVA indicated a $0.67^{\circ} \mathrm{C}$ increase in water temperature between Day 22 and Day 40 and a $0.08{ }^{\circ} \mathrm{C}$ decrease between TBZ-contaminated and uncontaminated microcosms (Table 2). $\mathrm{pH}$ varied significantly among sampling dates and between drought and TBZ treatments (Table 2) but the detected differences did not exceed $0.11 \mathrm{pH}$ unit. A slight decrease in dissolved oxygen concentration (0.26 mg L-1) occurred between Day 22 and Day 40. NH4+ and PO43- concentrations were not affected by TBZ contamination or by drought conditions (Table 2). However, NO3- and NO2- concentrations were significantly lower (by 1.1 and $0.08 \mathrm{mg} \mathrm{L}-1$, respectively) in permanently-immersed than in drought-exposed microcosms. 


\begin{tabular}{|c|c|c|c|c|}
\hline & Ic & Itbz & $D c$ & Dtbz \\
\hline Temperature $\left({ }^{\circ} \mathrm{C}\right)$ & $19.9 \pm 0.3$ & $19.8 \pm 0.4$ & $19.9 \pm 0.3$ & $19.8 \pm 0.3$ \\
\hline pH & $8.3 \pm 0.1$ & $8.2 \pm 0.1$ & $8.3 \pm 0.1$ & $8.3 \pm 0.1$ \\
\hline Conductivity $\left(\mu \mathrm{S} \mathrm{cm}^{-1}\right)$ & $400.2 \pm 56.5$ & $410.0 \pm 59.9$ & $443.9 \pm 53.1$ & $453.4 \pm 54.4$ \\
\hline Dissolved oxygen $\left(\mathrm{mg} \mathrm{L}^{-1}\right)$ & $8.94 \pm 0.13$ & $8.98 \pm 0.12$ & $8.93 \pm 0.21$ & $8.97 \pm 0.12$ \\
\hline $\mathrm{NO}_{3}^{-}\left(\mathrm{mg} \mathrm{L}^{-1}\right)$ & $8.51 \pm 1.56$ & $8.86 \pm 0.92$ & $8.54 \pm 2.86$ & $8.84 \pm 3.56$ \\
\hline $\mathrm{NO}_{2}^{-}\left(\mathrm{mg} \mathrm{L}^{-1}\right)$ & $0.06 \pm 0.05$ & $0.04 \pm 0.06$ & $0.11 \pm 0.08$ & $0.08 \pm 0.05$ \\
\hline $\mathrm{NH}_{4}^{+}\left(\mathrm{mg} \mathrm{L}^{-1}\right)$ & $0.01 \pm 0.00$ & $0.01 \pm 0.00$ & $0.04 \pm 0.05$ & $0.02 \pm 0.02$ \\
\hline $\mathrm{PO}_{4}{ }^{3-}\left(\mathrm{mg} \mathrm{L}^{-1}\right)$ & $0.03 \pm 0.02$ & $0.02 \pm 0.00$ & $0.02 \pm 0.00$ & $0.02 \pm 0.00$ \\
\hline DOC $\left(\mathrm{mg} \mathrm{L}^{-1}\right)$ & $8.66 \pm 5.58$ & $10.97 \pm 7.57$ & $17.36 \pm 6.20$ & $18.92 \pm 6.86$ \\
\hline
\end{tabular}

Table 1. Physical-chemical characteristics (mean \pm standard deviation, $n=5$ ) of water in the 4 treatments before water renewal on Days 4, 13, 22, 31, and 40 during the 40day experiment.

TBZ was not detected in the drilled groundwater used to fill the uncontaminated microcosms (Ic and Dc). TBZ concentrations measured in the contaminated tank used to fill the contaminated microcosms (Itbz and Dtbz) varied between 15.2 and $22.7 \mu \mathrm{g} \mathrm{L}-1$ (mean \pm s.d. over time $=17.1 \pm 2.6 \mu \mathrm{g} \mathrm{L}-1)$ during the experiment (Fig. 2). A marked dissipation of dissolved TBZ concentration was detected in contaminated channels (Itbz and Dtbz) (Fig. 2). Nevertheless, although this dissipation was very high during the first days (e.g., about $69 \%$ between day 0 and day 4 in Itbz and Dtbz), it was gradually attenuated over time to reach negligible (Itbz) or moderate (i.e., about $12 \%$ in Dtbz) levels by the end of the experiment.

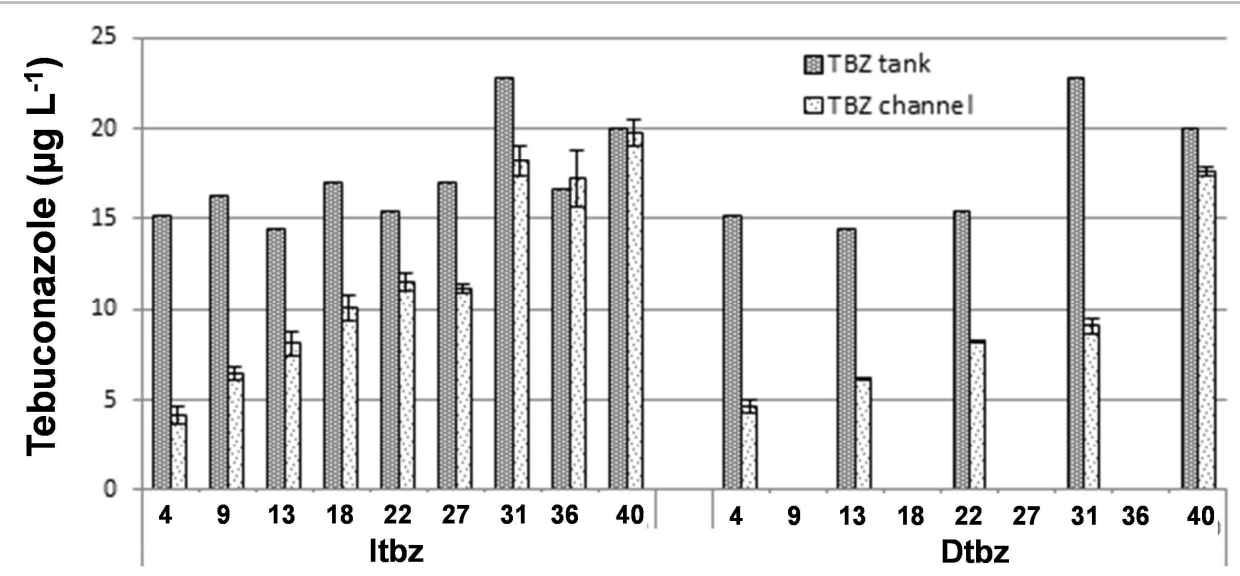

Fig. 2. Mean concentrations of dissolved tebuconazole ( \pm s.d.; $n=3$ ) in the contaminated microcosms (Itbz and Dtbz) before each water renewal and in the tank used to supply microcosms with contaminated water. 


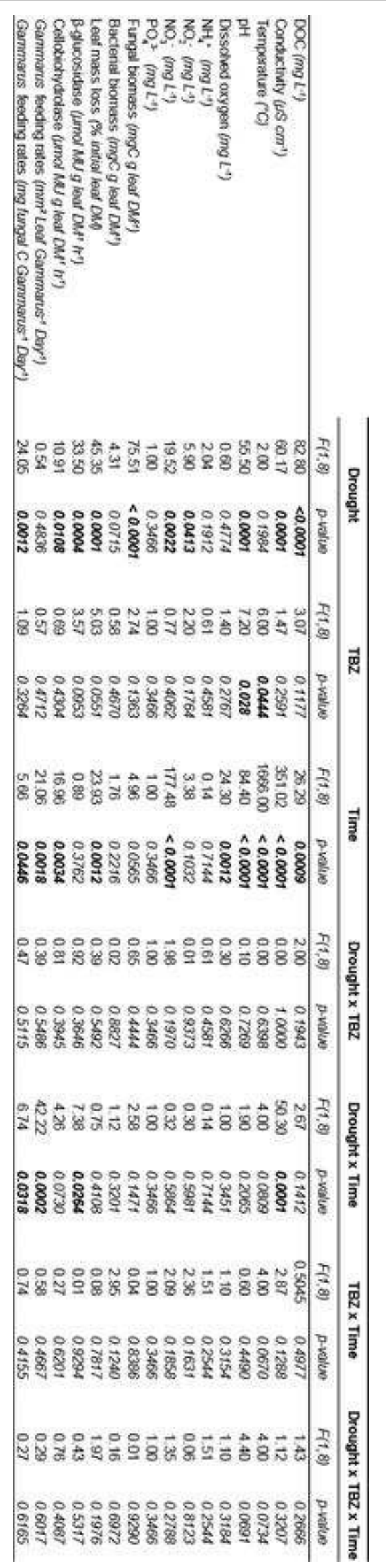

Table 2. Results of ANOVA testing the effect of drought, TBZ and time on leaf mass loss, microbial biomass and activities, Gammarus feeding rate and water physicalchemical characteristics. Significant differences are indicated in bold. 


\subsection{Structural characteristics of microbial communities}

Fungal biomass on leaves increased slightly, but not significantly $(p=0.0565)$, over time and was not significantly impacted by TBZ contamination ( $p=0.1363$; Fig. 3 , Table 2$)$. Mean fungal biomass was 1.8 fold higher (Table 2) in drought-exposed microcosms than in permanently-immersed microcosms.

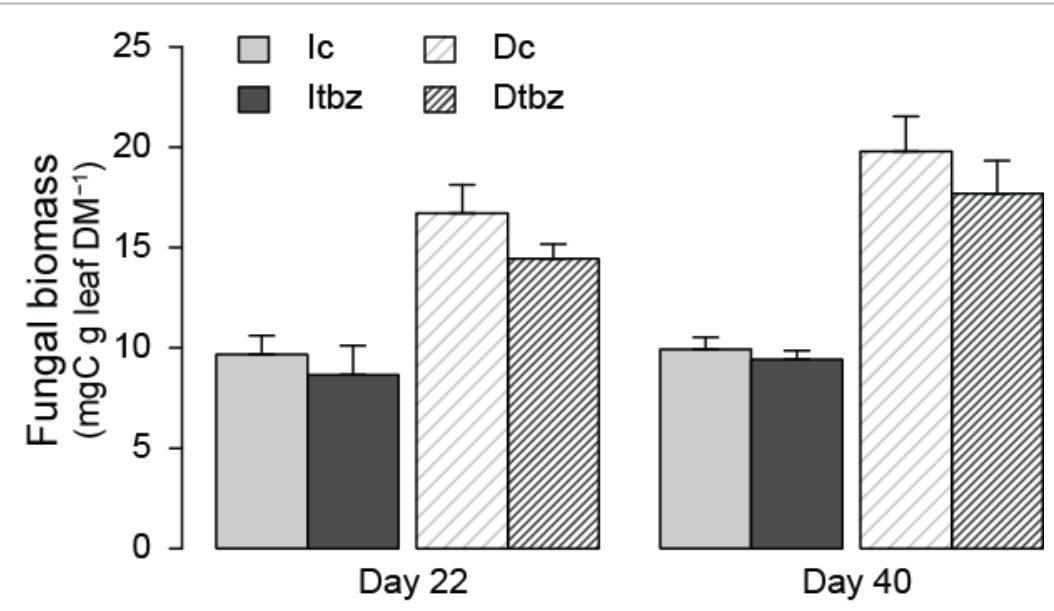

Fig. 3. Mean fungal biomass ( \pm s.e.; $n=3$ ) on leaves collected in the four treatments (Ic, Itbz, Dc, Dtbz) at days 22 and 40.

Bacterial biomass (Supplementary Fig. 1) varied from 0.04 and $0.09 \mathrm{mgC} \mathrm{g}$ leaf $\mathrm{DM}-1$, accounting for $1 \%$ of total microbial biomass on leaves, and without significant difference between drought or TBZ conditions or between sampling times (Table 2).

PERMANOVA indicated that drought and TBZ contamination had a significant influence on fungal community structure (assessed by PCR-ARISA) but their effects varied among sampling dates (Fig. 4A, Table 3). Drought and immersed microcosms had different community structure at Day 22 (post-hoc test, p-value $=0.0265$ ) and Day 40 (post-hoc test, $\mathrm{p}$-value $=0.0009$ ). Fungal community structure varied significantly between sampling dates in drought (post-hoc test, $p$-value $=0.0040$ ) and immersed (post-hoc test, $p$-value $=0.0180$ ) microcosms. The structure of fungal communities differed significantly between sampling dates in TBZ-contaminated microcosms (post-hoc test, $\mathrm{p}$-value $=0.0045$ ) but remained stable in uncontaminated microcosms (post-hoc test, $p$-value $=0.3769$ ). Fungal community structure was significantly different between uncontaminated and TBZ-contaminated microcosms at Day 22 (post-hoc test, p-value $=0.0048$ ) but not at Day 40 (post-hoc test, pvalue $=0.9477)$.

Bacterial community structure (assessed by PCR-ARISA) varied significantly among drought conditions and sampling dates (Fig. 4B, Table 3). Post-hoc comparisons indicated that the structure of bacterial communities varied significantly between sampling dates in drought (post-hoc test, $p$-value $=0.0024$ ) and immersed (post-hoc test, p-value $=0.0053$ ) microcosms. Bacterial community structure was significantly different between drought and immersed microcosms at Day 22 (post-hoc test, p-value $=0.0046$ ) and Day 40 (post-hoc test, p-value $=0.0024$ ) . 

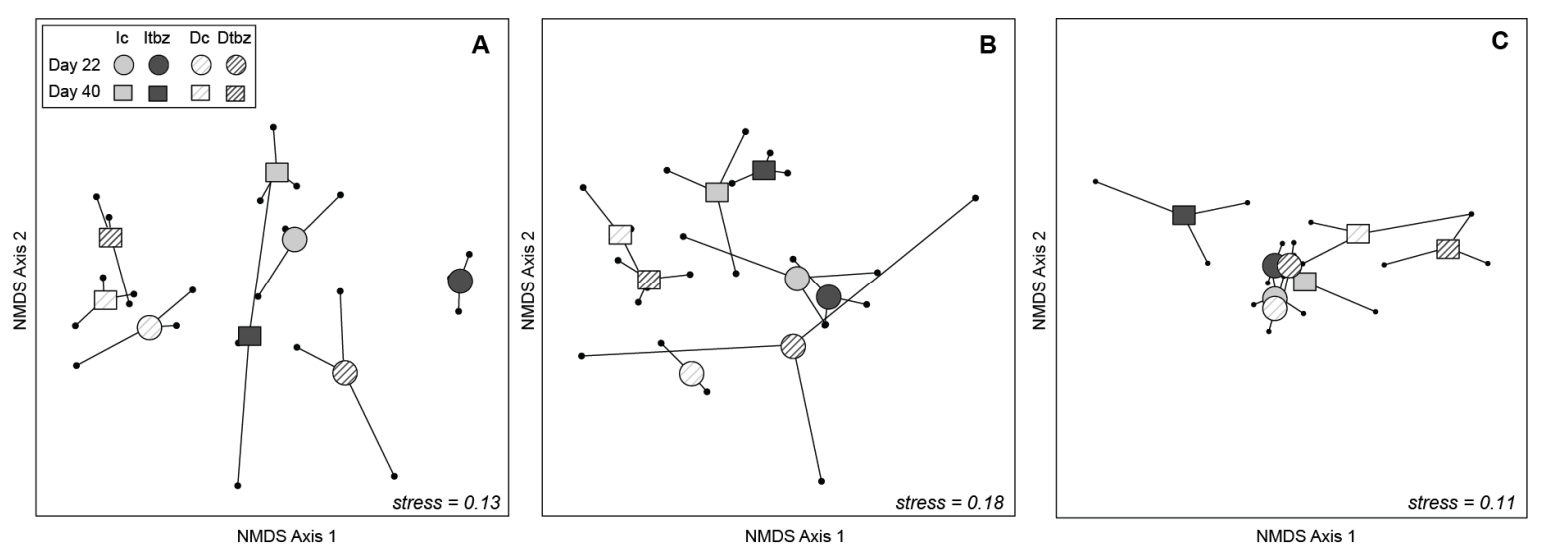

Fig. 4. Non-metric multidimensional scaling (NMDS) plot using fungal $(A)$ and bacterial (B) PCR-ARISA community profiles and fungal community structure based on taxonomica analyses (C) obtained at day 22 (circles) and day 40 (squares). For each treatment, large symbols represent centre of gravity and lines show measures of dispersion $(n=3)$. Stress values below 0.2 suggest that the ordination correctly represents the dissimilarity among samples.

\begin{tabular}{|c|c|c|c|c|c|c|c|}
\hline & \multirow[b]{2}{*}{ df } & \multicolumn{2}{|c|}{$\begin{array}{l}\text { Fungal community structure } \\
\text { (ARISA) }\end{array}$} & \multicolumn{2}{|c|}{$\begin{array}{c}\text { Bacterial community } \\
\text { structure (ARISA) }\end{array}$} & \multicolumn{2}{|c|}{$\begin{array}{c}\text { Fungal community } \\
\text { structure (Taxonomic) }\end{array}$} \\
\hline & & $\mathrm{F}$ & $p$-value & & & & \\
\hline Drought & 1 & 11.05 & 0.0001 & 7.42 & 0.0001 & 5.43 & 0.0004 \\
\hline TBZ & 1 & 4.18 & 0.0039 & 1.60 & 0.1609 & 1.41 & 0.2106 \\
\hline Time & 1 & 6.56 & 0.0004 & 6.53 & 0.0001 & 5.63 & 0.0001 \\
\hline Drought $x$ TBZ & 1 & 1.94 & 0.0908 & 1.45 & 0.2055 & 1.87 & 0.1065 \\
\hline Drought $\mathrm{x}$ Time & 1 & 2.47 & 0.0413 & 3.77 & 0.0021 & 3.60 & 0.0091 \\
\hline TBZ x Time & 1 & 3.00 & 0.0196 & 0.25 & 0.9506 & 1.23 & 0.2860 \\
\hline Drought $x$ TBZ $x$ Time & 1 & 1.27 & 0.2516 & 1.47 & 0.2013 & 2.01 & 0.0870 \\
\hline Residual & 16 & & & & & & \\
\hline Total & 23 & & & & & & \\
\hline
\end{tabular}

Table 3. Results of PERMANOVA testing the effect of Drought, TBZ and time on fungal and bacterial community structure. Significant differences are indicated in bold.

Taxonomic analysis of the hyphomycete species that colonized the leaves revealed that species richness decreased between Day 22 and Day 40 whatever the treatment (Table 4). PERMANOVA indicated a significant influence of drought and time on hyphomycete community structure (Table 3 ). Community structure differed significantly between sampling dates in drought (post-hoc test, $p$-value $=0.0048$ ) and immersed (post-hoc test, $p$-value $=$ 00.0047) microcosms (Fig. 4C). Drought had no influence at Day 22 (post-hoc test, $p$-value = 0.2879 ) but a significant effect was detected at Day 40 (post-hoc test, $p$-value $=0.0124$ ). Permanently-immersed assemblages (Ic and Itbz) had greater relative abundances of Anguillospora longissima and Clavariopsis aquatica species, accounting for $56 \%$ to $100 \%$ ( Table 4) of total hyphomycete species abundance, whereas temporary-drought microcosms (Dc and Dtbz) were mostly dominated by Tetracladium marchalianu, accounting for more than $79 \%$ of total hyphomycete species abundance. Although C. aquatica tended to be more abundant in TBZ-contaminated than uncontaminated microcosms (except in drought treatments at Day 40, Table 4), we found no effect of TBZ on taxonomic composition of the hyphomycetes community (Table 3). 


\begin{tabular}{|c|c|c|c|c|c|c|c|c|}
\hline & \multicolumn{4}{|c|}{ Day 22} & \multicolumn{4}{|c|}{ Day 40} \\
\hline & Ic & Itbz & Dc & Dtbz & Ic & Itbz & Dc & Dtbz \\
\hline Anguillospora longissima & $14.1 \pm 12.4$ & $24.4 \pm 6.4$ & $10.0 \pm 4.0$ & $4.2 \pm 4.3$ & $40.9 \pm 34.6$ & $29.6 \pm 33.9$ & $4.6 \pm 5.1$ & $18.5 \pm 32.1$ \\
\hline Articulospora tetracladia & nd & $0.3 \pm 0.5$ & $0.7 \pm 0.6$ & nd & nd & nd & nd & nd \\
\hline Clavariopsis aquatica & $32.1 \pm 23.5$ & $42.4 \pm 4.7$ & $2.1 \pm 2.5$ & $13.8 \pm 12.3$ & $33.8 \pm 36.6$ & $55.6 \pm 38.5$ & $7.5 \pm 10.9$ & nd \\
\hline Heliscus lugdunensis & $1.0 \pm 1.8$ & nd & nd & nd & nd & $3.7 \pm 6.4$ & nd & $2.1 \pm 3.6$ \\
\hline Lemonniera $s p$ & $2.9 \pm 1.8$ & $6.2 \pm 6.1$ & $1.3 \pm 1.1$ & $0.2 \pm 0.3$ & $8.7 \pm 11.3$ & nd & nd & nd \\
\hline Lemonniera terrestis & $1.7 \pm 2.9$ & nd & $0.1 \pm 0.2$ & $1.1 \pm 1.7$ & nd & nd & nd & nd \\
\hline Lemonniera aquatica & nd & nd & nd & nd & nd & nd & $1.7 \pm 2.9$ & nd \\
\hline Tetracladium marchalianum & $46.2 \pm 31.1$ & $22.1 \pm 2.2$ & $81.5 \pm 9.0$ & $72.8 \pm 20.9$ & $11.5 \pm 2.6$ & nd & $84.6 \pm 17.9$ & $79.4 \pm 30.4$ \\
\hline Tetracladium setigerum & $0.2 \pm 0.4$ & $0.4 \pm 0.7$ & nd & $0.1 \pm 0.1$ & nd & nd & $1.0 \pm 1.8$ & nd \\
\hline Tricladium angulatum & $0.5 \pm 0.8$ & nd & $0.1 \pm 0.2$ & nd & nd & nd & nd & nd \\
\hline Tumularia aquatica & $1.3 \pm 2.3$ & $4.2 \pm 4.0$ & $2.8 \pm 2.4$ & $7.9 \pm 6.2$ & $1.5 \pm 2.6$ & $11.1 \pm 19.2$ & $0.6 \pm 1.1$ & nd \\
\hline Volucrispora graminea & nd & nd & $1.4 \pm 2.0$ & nd & $3.7 \pm 6.4$ & nd & nd & nd \\
\hline species richness & $6 \pm 1$ & $5 \pm 1$ & $7 \pm 2$ & $5 \pm 2$ & $4 \pm 1$ & $3 \pm 2$ & $3 \pm 2$ & $2 \pm 1$ \\
\hline
\end{tabular}

Table 4. Mean relative abundance and mean species richness ( \pm s.d.; $n=3$ ) of leafassociated aquatic hyphomycetes in the four treatments (Ic, Itbz, Dc, Dtbz) at days 22 and 40 .

\subsection{Functionality of microbial communities}

In the permanently immersed microcosms, leaf mass loss reached about $34 \%$ at the end of the experiment, without significant effect of TBZ, whatever the sampling time (Fig. 5 and Table 2). Leaf mass loss was significantly reduced (Table 2 ) in drought microcosms (Dc and Dtbz). Despite a lower leaf mass loss in drought-TBZ contaminated microcosms (about 19\% mass loss at day 40) than in drought-uncontaminated microcosms (about 25\% at day 40), the effect of TBZ was not strong enough to induce a significant difference $(p=0.0551$; Table 2).

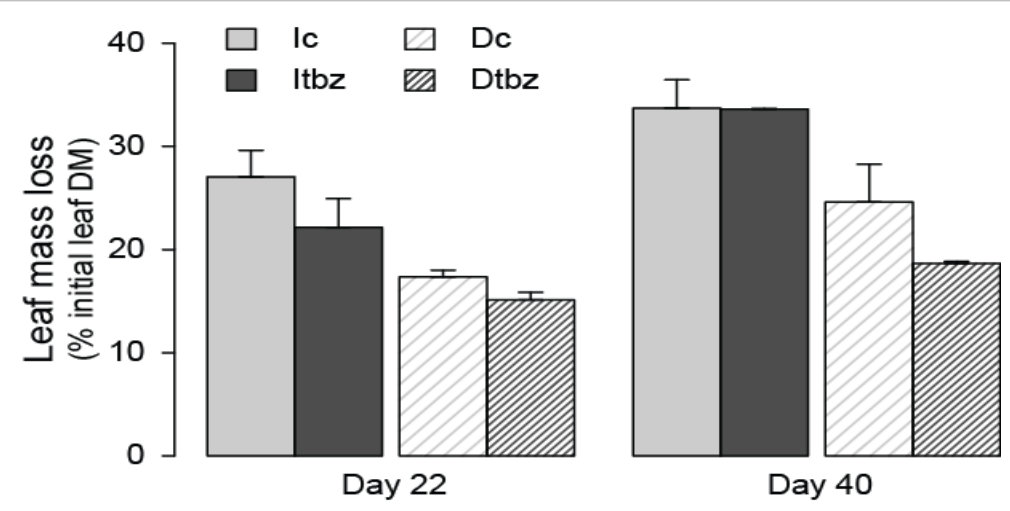

Fig. 5. Mean mass loss ( \pm s.e.; $n=3$ ) for Alnus leaves in the four treatments (Ic, Itbz, Dc, Dtbz) at Days 22 and 40.

Similar trends were observed for extracellular $\beta$-glucosidase (Fig. 6A) and cellobiohydrolase (Fig. 6B) activities. The two enzymatic activities were significantly lower in drought than in permanently-immersed microcosms (Table 2). Cellobiohydrolase activity increased significantly during the experiment (Table 2) as was the case for $\beta$-glucosidase in permanently-immersed microcosms. However, $\beta$-glucosidase did not vary among sampling dates in drought microcosms (post-hoc test, $p$-value $=0.2436$ ). While the lower rates of enzymatic activity were observed in drought-TBZ contaminated microcosms at the end of the experiment (Fig. 6), no significant influence of TBZ contamination was detected (Table 2). 


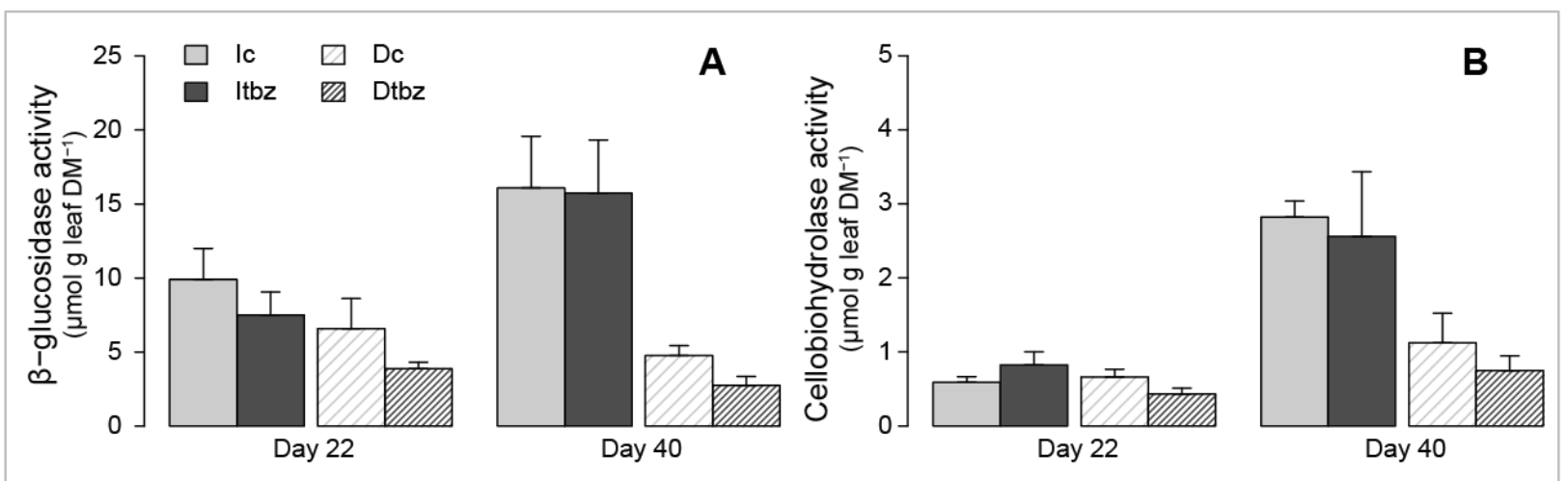

Fig. 6. Mean $\beta$-glucosidase $(A)$ and cellobiohydrolase $(B)$ activities ( \pm s.e.; $n=3$ ) on leaves collected in the four treatments (Ic, Itbz, Dc, Dtbz) at days 22 and 40.

\subsection{Feeding rates of Gammarus fossarum}

The significant influence of drought conditions on the feeding rates of $\mathrm{G}$. fossarum expressed as $\mathrm{mm} 2$ leaf varied among sampling dates (Table 2). Post-hoc comparisons indicated that feeding rates of $\mathrm{G}$. fossarum remained stable between day 22 and day 40 for leaves collected in permanently-immersed microcosms (Ic and Itbz, p-value $=0.2142$, Fig. 7). Conversely, feeding rates varied strongly between sampling times in drought treatments. $G$. fossarum feeding rates were significantly higher in drought microcosms than in immersed microcosms at day 22 (post-hoc test, $p$-value $=0.0242$ ) while the opposite pattern was detected at Day 40 (post-hoc test, $p$-value $=0.038$ ).

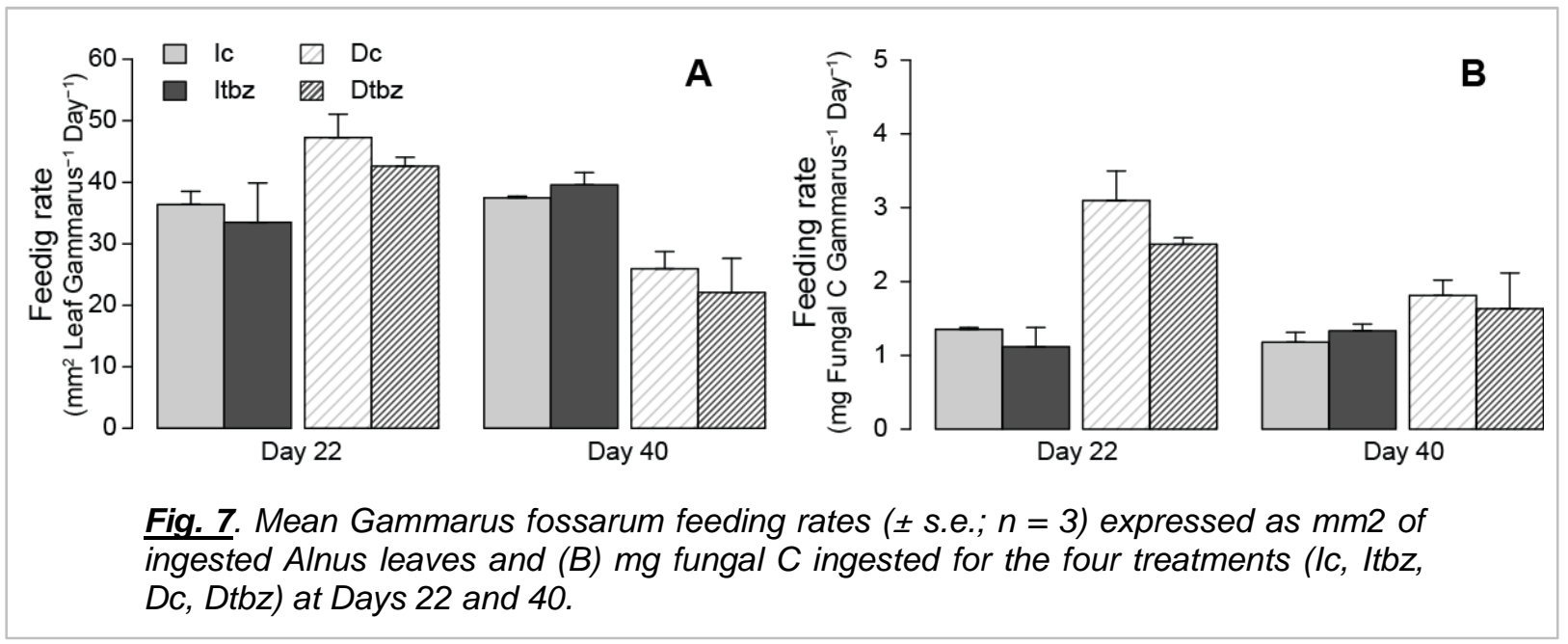

Based on results expressed as ingested fungal C (mg Fungal C Gammarus-1 Day-1), feeding rates were higher in drought microcosms ( $D c$ and $D t b z$ ) than in permanentlyimmersed microcosms (Ic and Itbz) at Day 22 (Fig. 7B, post-hoc test, p-value $=0.0007$ ), while no difference was detected at Day 40 (post-hoc test, $p$-value $=0.1304$ ). Feeding rates decreased significantly between Day 22 and Day 40 (post-hoc test, $p$-value $=0.0079$ ) in drought microcosms while it remained stable in immersed microcosms during the course of the experiment (post-hoc test, $p$-value $=0.8816$ ). TBZ had no influence on feeding rates of G. fossarum expressed as $\mathrm{mm} 2$ leaf or $\mathrm{mg}$ Fungal $\mathrm{C}$ (Table 2). 


\section{Discussion}

\subsection{Effects of individual stressors on microbial leaf litter decomposition}

Unexpectedly and against our first hypothesis, TBZ stress applied alone (i.e., under permanently-immersed conditions) had no effect other than a transient change in genetic structure of fungal communities at Day 22 (Fig. 4). This apparent lack of TBZ effect on heterotrophic microbial communities colonizing alder leaves is inconsistent with most previous studies (Bundschuh et al., 2011, Zubrod et al., 2011 and Artigas et al., 2012). Since the exposure duration used here (40 days) was comparable to that used by Artigas et al. (2012) and longer than the roughly two weeks used in Zubrod et al. (2011) and Bundschuh et al. (2011), the absence of drastic effects in the present study could be linked to the use of a lower TBZ concentration (average concentrations of $17.1 \mu \mathrm{g} \mathrm{L}-1$ ) compared to those previous studies, where nominal or measured TBZ concentrations ranged from 33 up to 500 $\mu \mathrm{g} L-1$. Note, however, that the comparison of exposure level between studies is rendered difficult by the differences in experimental systems and procedures conditioning the dynamics of dissolved TBZ whose concentrations fluctuate over time (due to adsorption, absorption and desorption phenomena), as shown here. For example, Zubrod et al. (2015a) found effects on fungal biomass and bacterial density at a TBZ concentration of only $5 \mu \mathrm{g}$ L-1. Nevertheless, exposure level is not the only factor that shapes microorganism responses to toxicants, especially in complex natural communities (Pesce et al., 2009). Indeed, the response of natural microbial communities to toxicant exposure likely depends on a combination of parameters such as initial composition, physiological status, or the environmental characteristics of the sampling site and the experimental systems. This could explain why Dimitrov et al. (2014) observed no response of fungal communities decomposing Alnus leaves at very high TBZ concentrations (238 $\mu \mathrm{g} \mathrm{L-1)}$ over a 52-day exposure in a semi-field study (experimental ditches). Overall, the great heterogeneity among studies on microbial responses to TBZ confirms the need to increase the ecological relevance of ecotoxicological risk assessment by considering the biodiversity, functions and response dynamics involved (Clements and Rohr, 2009 and Geiszinger et al., 2009).

Unlike fungicide exposure, the drought treatment strongly impacted microbial community structure and activities, inhibiting the LLD process and leading to indirect effects on macroinvertebrate feeding behavior. In the absence of TBZ, LLD was reduced by about onethird in drought microcosms compared to permanently-immersed microcosms (Fig. 5). Similar effects of drought on LLD were described in previous studies (e.g., Langhans and Tockner, 2006 and Foulquier et al., 2015). Nevertheless, the observed increase in fungal biomass (Fig. 3) in the drought treatment was contrary to most studies reporting a decrease in fungal biomass on leaves subjected to drying stress (Bruder et al., 2011 and Foulquier et al., 2015). Here, fungal biomass developing on leaves was estimated using concentration of ergosterol, a fungal-specific sterol present in cell plasma membrane. Although ergosterol content was shown to vary among species of hyphomycetes and with environmental conditions (Bermingham et al., 1995), it is considered as an appropriate descriptor of fungal biomass on submerged leaves (Gessner and Chauvet, 1993 and Gessner, 2005). The observed increase in fungal biomass points to the hypothesis that drying stress could have selected for hyphomycete mycelia with thicker membranes (greater ergosterol accumulation) to resist desiccation. Indeed, changes in fungal biomass were also accompanied by changes in fungal community structure (PCR-ARISA profiles; Fig. 4) and composition (taxonomical analysis; Table 4) under drought exposure. While modifications in microbial community structure in response to drying events have been reported for temporary streams and wetland sediments (Febria et al., 2012 and Foulquier et al., 2013), the effects of repeated emersion events on the structure of fungal communities associated with leaf substrata remain overlooked (Foulquier et al., 2015). Here, drought stress resulted in a shift that replaced the species $A$. longissima and $C$. aquatica by $T$. marchalianum. However, previous estimates of mycelial ergosterol content in these aquatic hyphomycetes ( Gessner and Chauvet, 1993) could not explain the two-fold increase in ergosterol observed here. Membrane sterols are involved in stress tolerance, and a previous study showed that ergosterol helped stabilize membrane during heat and ethanol stress (Swan and Watson, 
1998) and was involved in the resistance of terrestrial fungi to air-drying (Dupont et al., 2012). It is unclear whether phenotypic plasticity and increased production of membrane ergosterol in response to drying stress could explain the observed increase in ergosterol accumulated on leaves. However, note that Langhans and Tockner (2006) also observed a winter-season increase in ergosterol content in leaves submitted for 30 days to five successive dry/wet cycles compared to permanently-immersed leaves, without significant difference in LLD. Their study revealed that fungal biomass estimated as ergosterol content can be influenced by duration and frequency of drying events and their interaction. Here, unlike the increase in estimates of fungal and bacterial biomass detected in the drought treatment, cellobiohydrolase and $\beta$-glucosidase enzyme activities remained low (Fig. 6), as previously shown (Foulquier et al., 2015). Combined with reduced abiotic leaching, this reduction in enzymatic activities could partly explain the higher DOC concentrations detected in drought microcosms in comparison with immersed microcosms. Most of the DOC leached from leaves was repeatedly flushed away the microcosms during water renewal that occurred more frequently in immersed microcosms (see Fig. 1) in comparison with drought microcosms. As a consequence, significant amount of DOC were still released from leaves and detected in drought microcosms at the end of the experiment while most of the DOC had been released earlier in permanently immersed microcosms.

The observed decoupling between microbial biomass (especially that of fungi estimated as ergosterol content) and enzymatic hydrolytic activities could involve a trade-off between stress tolerance and cell functioning in drought-exposed microbial communities. Dry stress tolerance is governed by the coordinated response of multiple functional traits such as cellwall thickness or production of intracellular osmolyte and/or heat-shock proteins (Crowther et al., 2014). Response to drying stress is energetically expensive and occurs at the cost of other metabolic processes (Schimel et al., 2007). An inability to bear this energetic cost leads cells to dormancy or ultimately death (Manzoni et al., 2014). The observed increase in fungal biomass in drought treatments could thus be associated with dormant or dead cells remaining attached on leaf material (Mille-Lindblom et al., 2004). As the remaining active cells allocate energy to cell maintenance in response to drying stress, less energy gets allocated to extracellular enzyme production and the associated decomposition of leaf litter. This confirms the interest of considering extracellular enzymatic potential as a functional descriptor for monitoring (multi) stress-induced impairment of microbial capacities to degrade organic matter and altered carbon cycling in rivers (Artigas et al., 2012).

\subsection{Effects of combined stressors on microbial leaf litter decomposition}

Previous studies focusing on a comparable multiple stress case (i.e., hydrological disturbance and toxicants) have investigated periphytic biofilm (Corcoll et al., 2015 and Proia et al., 2013) or zooplankton (Stampfli et al., 2013) communities. To our knowledge, this is the first study to focus on microbial communities associated with decomposing leaves.

In a previous multi-stressor study (Stampfli et al., 2013), the overwhelming effect of hydrological disturbance on zooplankton limited the potential for detection of interactive effects with the insecticide esfenvalerate. Similarly, in our study most of the observed effects in leaf-microbial communities were related to the drought stress rather than the TBZ stress. Hydrological disturbances, particularly drying stress, encompass multiple stresses including a physiological stress, by impeding resource acquisition through the limitation of substrate and nutrient diffusion, combined with osmotic stress when water potential declines (Schimel et al., 2007). Although the combined effects of drought events and toxicants on aquatic microbial communities are still largely unknown, recent studies have evidenced that drought episodes can influence benthic microorganism response to toxicants (Corcoll et al., 2015 and Proia et al., 2013). As recently observed by Corcoll et al. (2015), the modulation of toxicant effects by drought events differs according to microbial compartment targeted. The authors observed that bacterial and algal communities in biofilms became, respectively, less and more sensitive to pharmaceutical compounds when subjected to flow intermittency. Community response to multiple stressors depends on the ability of organisms to tolerate each stressor and on the possible occurrence of positive or negative co-tolerance (Tlili et al., 
2011). Exposure to a stressor combined with positive co-tolerance should reduce the impacts of another stressor, while negative co-tolerance is expected to increase sensitivity to a second stressor, thus resulting in a more pronounced impact (Vinebrooke et al., 2004). In our study, the lack of statistical interaction between drought and TBZ (Table 2) suggests an independent action of the two stressors. However, our results showed that functional responses observed on microbial communities (i.e., decrease in LLD (Fig. 5) and in enzymatic activities (Fig. 6)) were more pronounced when drought and TBZ stresses were applied together. While the combined effects on the structural parameters of microbial communities were less perceptible, it is interesting to note that fungal biomass on leaves in drought treatments was also slightly lower under fungicide exposure (Fig. 3). These results suggest that the effects of drought and TBZ contamination were amplified when applied simultaneously on leaf microbial communities, especially if we consider the fact that exposure to TBZ was lower in drought-contaminated microcosms in comparison to permanently-immersed microcosms that were exposed continuously to TBZ. In a global change context, and assuming that pollutant toxicity to benthic microbial communities can increase after drought episodes (Proia et al., 2013), this finding reinforces the need to investigate combined effects of hydrological disturbance and toxicants on aquatic biological communities (Stampfli et al., 2013).

The relative influence of drought and fungicide treatments on leaf litter decomposition found here, like the general outcome of the study, need to be recasted in light of the ecological realism of our experimental design. The high frequency of drying events should be seen in the context of rivers experiencing regulated flow or daily peak hydropower effects with drying events occurring rapidly during low-flow periods (Moog, 1993 and Jones, 2014). Here, dry periods were simulated by allowing microcosms to rapidly empty, which is in contrast to river ecosystems experiencing seasonal drying events where water-level drawdown generally leads to the formation of isolated pools and, among other stressors (e.g., increased temperature, reduced dissolved oxygen), a concentration of nutrients and contaminants that could exacerbate the toxic effects (through a decrease in dilution capacity; Proia et al., 2013). Even though we observed that the dynamics of dissolved fungicide concentrations differed between permanent and intermittent flow regimes, further studies should include measurements of the fungicide accumulation on leaf material, in order to accurately evaluate and compare community exposure levels.

\subsection{Drought and TBZ stress effects along the aquatic detrital foodweb}

Leaf-shredding invertebrates play a critical role in LLD and their activity can account for up to $60 \%$ of leaf mass loss in river ecosystems (Baldy and Gessner, 1997). Shredder feeding rates are indirectly influenced by the activity and diversity of microbial decomposers that enhance leaf palatability and can also modulate leaf consumption by shredders through selective feeding on particular hyphomycete taxa (Bärlocher and Kendrick, 1975, Arsuffi and Suberkropp, 1989 and Bundschuh et al., 2011). Consequently, any modification in the structure and function of leaf-associated microbial communities can potentially alter the transfer of matter and energy to the upper trophic levels in detrital foodwebs (Zubrod et al., 2011). Here, fungal biomass and feeding rates were poorly correlated. This is in line with previous studies (Rong et al., 1995 and Zubrod et al., 2015b) that observed no significant correlations between leaf ergosterol contents and consumption by shredding invertebrates. Conversely, Bärlocher (1985) reported strong relationships between leaf nutritional quality (characterized by nitrogen-rich fungal biomass accumulation) and invertebrate feeding, in accordance with the concept of compensatory feeding (i.e., an increase in leaf consumption by shredders to fulfill their energetic requirements despite the lower quality food on offer). Here, invertebrate Gammarus feeding rates followed complex patterns according to litter decomposition stage ( Fig. 7). At day 22, feeding rates, both expressed as consumed leaf surface and fungal biomass (Fig. 7A and B), shows that drought conditions stimulated Gammarus shredding activity at Day 22. At the end of experiment (Day 40), the amount of ingested leaves (based on leaf surface) strongly decreased under drought stress (Dc and Dtbz; Fig. 7A). However, when ingested leaf surfaces were converted to ingested fungal biomass, no significant difference was observed between drought and immersed treatments 
(Fig. 7B). Accordingly, this decrease in the quantity of consumed leaves could suggest a compensatory feeding mechanisms, since less leaf surface was required to meet nutritional requirements, based on fungal biomass. Another potential mechanism for the reduced Gammarus feeding rates (as $\mathrm{mm} 2$ eaf) could be related to the drastic reduction in hyphomycete richness and the changes in fungal community composition after 40 days in all treatments. The greatest reduction was observed under drought conditions where communities were dominated by $\mathrm{T}$. marchalianum species at the end of the experiment. This species was shown to be unpalatable/rejected by gammarids in previous ecological and ecotoxicological studies e.g. ( Gonçalves et al., 2014). As a consequence, it cannot be excluded that an avoidance mechanism was responsible for the decrease in Gammarus feeding rates on drought-stressed leaves at the end of the experiment. Even if consumption rates of invertebrates have been observed to decrease during leaf conditioning ( Anderson and Sedell, 1979), invertebrate feeding rates in our experiment did not significantly differ between Days 22 and 40 in permanently immersed treatments (Ic and Itbz) but it was the case in drought treatments (Dc and Dtbz) (Fig. 7). This observation suggests that feeding behavior of invertebrates was not affected by over conditioning (i.e., a relative increase in recalcitrant over easily assimilated compounds resulting from prolonged decomposition (Anderson and Sedell, 1979) of alder leaves. Moreover, the leaf mass remaining at day 40 was around $40 \%$ (immersed treatments), an amount sufficient to supply organic matter to microorganisms and invertebrates without strong resource limitation. Generally, our results clearly demonstrated a negative effect of drought on quantity of leaves decomposed by microbial communities or ingested by Gammarus after 40 days, and this effect was sharper when the drought stress was combined with fungicide exposure, due to a possible independent action, as mentioned above. Given the ecological importance of LLD in aquatic ecosystems, this suggests a potential cascading effect of multiple abiotic stressors on ecosystem functioning, with effects propagating up the detrital food web, from decomposers to detritivores involved in organic matter processing and the recycling of nutrients. In a perspective of ecological risk assessment and ecosystem management for sustainability, these findings argue the need for deeper insight into how multiple stressors can affect aquatic biota and functioning. Classical ecotoxicological risk assessment based on laboratory toxicity data gained from bioassays restricted to individual toxicant/species/functional endpoints is likely to over or underestimate the impact of contaminants at the ecosystem level by ignoring the complexity of biotic communities and their interactions. Our findings demonstrate that ecological relevance of ecotoxicological risk assessment can be increased by considering both structural and functional response of communities and interactions between trophic levels.

\section{Acknowledgments}

The authors thank A-T-T for proofreading the language content, Bernadette Volat, Coline Bender, Christophe Rosy and Bernard Motte for their help with the field and laboratory work. The authors also thank Irstea's Water Chemistry Laboratory in Lyon, Hervé Quéau for technical assistance on feeding rate measurements and Jonathan Colombet for his help with the flow cytometry analyses.

\section{References}

Adis, J., Junk, W.J., 2002. Terrestrial invertebrates inhabiting lowland river floodplains of Central Amazonia and Central Europe: a review. Freshwater Biology, 47, 711-731.

Agatz, A., Ashauer, R., Brown, C. D., 2014. Imidacloprid perturbs feeding of Gammarus pulex at environmentally relevant concentrations. Environmental toxicology and chemistry, 33(3), 648-653.

Amalfitano, S., Fazi, S., Zoppini, A., Barra Caracciolo, A., Grenni, P., Puddu, A., 2007. Responses of benthic bacteria to experimental drying in sediments from mediterranean temporary rivers. Microbial Ecology 55, 270-279. 
Anderson, M.J., 2001. A new method for non-parametric multi variate analysis of variance. Austral Ecology 26, 32-46.

Anderson, M.J., 2005. PERMANOVA: a FORTRAN computer program for permutational multivariate analysis of variance. Department of Statistics, University of Auckland, New Zealand. www.stat.auckland.ac.nz/mja/prog/PERMANOVA.

Anderson, N., Sedell, J., 1979. Detritus processing by macroinvertebrates in stream ecosystems. Annual Review of Entomology 24, 351-377.

Arsuffi, T.L., Suberkropp, K., 1989. Selective feeding by shredders on leaf-colonizing stream fungi: comparison of macroinvertebrate taxa. Oecologia, 79, 30-37.

Artigas, J., Majerholc, J., Foulquier, A., Margoum, C., Volat, B., Neyra, M., Pesce, S., 2012. Effects of the fungicide tebuconazole on microbial capacities for litter breakdown in streams. Aquat. Toxicol., 122-123,197-205.

Baldy, V., Gessner, M.O., Chauvet, E., 1995. Bacteria, fungi and the breakdown of leaf litter in a large river. Oikos, 74, 93-102.

Baldy, V., Gessner, M.O., 1997. Towards a budget of leaf litter decomposition in a first-order woodland stream. Comptes Rendus de l'Academie des Sciences, Serie III. Sciences de la Vie/Life Sciences, 320, 747-758.

Bärlocher, F., Kendrick, B., 1975. Leaf-conditioning by microorganisms. Oecologia, 20, 359362.

Bärlocher, F., 1985. The role of fungi in the nutrition of stream invertebrates. Bot. J. Linn. Soc., 91, 83-94.

Bärlocher, F., 1992. Effects of drying and freezing autumn leaves on leaching and colonization by aquatic hyphomycetes. Freshwater Biol., 28, 1-7.

Bermingham, S., Maltby, L., Cooke, R.C., 1995. A critical assessment of the validity of ergosterol as an indicator of fungal biomass. Mycological Research 99, 479-484.

Besse, J.P., Coquery, M., Lopes, C., Chaumot, A., Budzinski, H., Labadie, P., Geffard, O., 2013. Caged Gammarus fossarum (crustacea) as a robust tool for the characterization of bioavailable contamination levels in continental waters: Towards the determination of threshold values. Water Res., 47, 650-660.

Borrel, G., Colombet, J., Robin, A., Lehours, A.C., Prangishvili, D., Sime-Ngando, T., 2012. Unexpected and novel putative viruses in the sediments of a deep-dark permanently anoxic freshwater habitat. ISME J., 6, 2119-2127.

Bruder, A., Chauvet, E., Gessner, M.O., 2011. Litter diversity, fungal decomposers and litter decomposition under simulated stream intermittency. Funct. Ecol., 25, 1269-1277.

Bundschuh, M., Zubrod, J.P., Kosol, S., Maltby, L., Stang, C., Duester, L., Schulz, R., 2011. Fungal composition on leaves explains pollutant-mediated indirect effects on amphipod feeding. Aquat. Toxicol., 104, 32-37.

Clements, W.H., Rohr, J.R., 2009. Community responses to contaminants: using basic ecological principles to predict ecotoxicological effects. Environ. Toxicol. Chem., 28, 17891800 .

Corcoll, N., Casellas, M., Huerta, B., Guasch, H., Acuña, V., Rodríguez-Mozaz, S., SerraCompte, A., Barceló, D., Sabater, S., 2015. Effects of flow intermittency and pharmaceutical exposure on the structure and metabolism of stream biofilms. Sci. Total Environ., 503-504, 159-170 
Corti, R., Datry, T., Drummond, L., Larned, S.T., 2011. Natural variation in immersion and emersion affects breakdown and invertebrate colonization of leaf litter in a temporary river. Aquat. Sci., 73, 537-550.

Corti, R., Datry, T., (in press) Terrestrial and aquatic invertebrates in the riverbed of an intermittent river: parallels and contrasts in community organisation. Freshwater Biology.

Coulaud, R., Geffard, O., Xuereb, B., Lacaze, E., Quéau, H., Garric, J., Charles, S., Chaumot, A., 2011. In situ feeding assay with Gammarus fossarum (Crustacea): Modelling the influence of confounding factors to improve water quality biomonitoring. Water Res.. 45, 6417-6429.

Crowther, T.W., Maynard, D.S., Crowther, T.R., Peccia, J., Smith, J.R., Bradford, M.A., 2014. Untangling the fungal niche: a trait-based approach. Front. Microbiol., 5, 579. doi: 10.3389/fmicb.2014.00579

Datry, T., Corti, R., Claret, C., Philippe, M., 2011. Flow intermittence controls leaf litter breakdown in a French temporary alluvial river: The "drying memory". Aquat. Sci., 73, 471483.

Datry, T., 2012. Benthic and hyporheic invertebrate assemblages along a flow intermittence gradient: effects of duration of dry events. Freshwater Biol., 57, 563-574.

Datry, T., Larned, S.T., Tockner, K., 2014. Intermittent rivers: A challenge for freshwater ecology. Bioscience, 64, 229-235.

Dimitrov, M.R., Kosol, S., Smidt, H., Buijse, L., Van den brink, P.J., Van Wijngaarden, R.P.A., Brock, T.C.M., Maltby, L., 2014. Assessing effects of the fungicide tebuconazole to heterotrophic microbes in aquatic microcosms. Sci. Total Environ., 490, 1002-1011.

Dudgeon, D., Arthington, A.H., Gessner, M.O., Kawabata, Z., Knowler, D.J., Lévêque, C., Naiman, R.J., Prieur-Richard, A.H., Soto, D., Stiassny, M.L., Sullivan, C.A., 2006. Freshwater biodiversity: importance, threats, status and conservation challenges. Biol. Rev., 81, 163182.

Dupont, S., Lemetais, G., Ferreira, T., Cayot, P., Gervais, P., Beney, L., 2012. Ergosterol biosynthesis: a fungal pathway for life on land? Evolution 66:2961-2968.

Febria, C.M., Beddoes, P., Fulthorpe, R.R., Williams, D.D., 2012. Bacterial community dynamics in the hyporheic zone of an intermittent stream. ISME J., 6, 1078-1088.

Foulquier, A., Volat, B., Neyra, N., Bornette, G., Montuelle, B., 2013. Long-term impact of hydrological regime on structure and functions of microbial communities in riverine wetland sediments. FEMS Microbiol. Ecol., 85, 211-226.

Foulquier, A., Artigas, J., Pesce, S., Datry, T., 2015. Drying responses of microbial litter decomposition and associated fungal and bacterial communities are not affected by emersion frequency. Freshw. Sci., 34, 1233-1244.

Geiszinger, A., Bonnineau, C., Faggiano, L., Guasch, H., Lopez-Daval, J., Proia, L., Ricart, M., Ricciardi, F., Rohr, J.R., Kerby, J.L., Sih, A., 2006. Community ecology as a framework for predicting contaminant effects. Trends Ecol. Evol., 21, 606-613.

Gessner, M.O., Chauvet, E., 1993. Ergosterol-to-biomass conversion factors for aquatic hyphomycetes. Appl. Environ. Microbiol., 59, 502-507.

Gessner, M.O., Chauvet, E., 1994. Importance of stream microfungi in controlling breakdown rates of leaf litter. Ecology, 75, 1807-1817. 
Gessner, M.O., Chauvet, E., 2002. A case for using litter breakdown to assess functional stream integrity. Ecol. Appl., 12, 498-510.

Gessner, M.O., Schmitt, A.L., 1996. Use of solid-phase extraction to determine ergosterol concentrations in plant tissue colonized by fungi. Appl. Environ. Microbiol., 62, 415-419.

Gessner, M. O. 2005. Ergosterol as a measure of fungal biomass. Pages 189-195 Methods to study litter decomposition. Graça MAS, Bärlocher F, Gessner MO. Springer.

Gonçalves, A. L., Chauvet, E., Bärlocher, F., Graça, M.A.S., Canhoto, C., 2014. Top-down and bottom-up control of litter decomposers in streams. Freshwater Biology 59, 2172-2182.

Graça, M.A.S., 2001. The role of invertebrates on leaf litter decomposition in streams - A review. Inter. Rev. Hydrobiol., 86, 383-393.

Ingold, C.T., 1975. An illustrated guide to aquatic and water-borne Hyphomycetes (Fungi imperfecti) with notes on their biology. Freshwater Biological Association, Scientific Publication, p. 30.

Jones, N.E., 2014. The dual nature of hydropeaking rivers: is ecopeaking possible? Riv. Res. Appl., 30, 521-526.

Langhans, S.D., Tockner, K., 2006. The role of timing, duration, and frequency of inundation in controlling leaf litter decomposition in a river-floodplain ecosystem (Tagliamento, northeastern Italy). Oecologia, 147, 501-509.

Larned, S., Datry, T., Robinson, C., 2007. Invertebrate and microbial responses to inundation in an ephemeral river reach in New Zealand: effects of preceding dry periods. Aquat. Sci., $69,554-567$.

Lenth, R.V., Hervé, M., 2015. Ismeans. R package version 2.15. R Foundation for Statistical Computing, Vienna, Austria, http://CRAN.R-project.org/package=Ismeans

Macneil, C., Dick, J.T.A., Elwood, R.W., 1997. The trophic ecology of freshwater Gammarus spp. (Crustacea: Amphipoda): problems and perspectives concerning the functional feeding group concept. Biological Reviews 72, 349-364.

Manzoni, S., Schaeffer, S.M., Katul, G., Porporato, A., Schimel, J.P., 2014. A theoretical analysis of microbial eco-physiological and diffusion limitations to carbon cycling in drying soils. Soil Biol. Biochem., 73, 69-83.

Mille-Lindblom, C., von Wachenfeldt, E., Tranvik, L.J., 2004. Ergosterol as a measure of living fungal biomass: persistence in environmental samples after fungal death. Journal of Microbiological Methods 59, 253-262.

Moog, O., 1993. Quantification of daily peak hydropower effects on aquatic fauna and management to minimize environmental impacts. Regul. Rivers Res. Manage. 1, 8, 5-14.

Oksanen, J., Blanchet, F.G., Kindt, R., Legendre, P., Minchin, P.R., O'Hara, R.B., Simpson, G.L., Solymos, P., Stevens, M.H.M., Wagner, H., 2015. vegan: Community Ecology Package. R package version 2.3-0. http://CRAN.R-project.org/package=vegan

Pesce, S., Batisson, I., Bardot, C., Fajon, C., Portelli, C., Montuelle, B., Bohatier, J., 2009; Response of spring and summer riverine microbial communities following glyphosate exposure. Ecotox. Environ. Safe., 72, 1905-1912

Pinheiro, J., Bates, D., DebRoy, S., Sarkar, D. and R Core Team, 2015. nlme: Linear and Nonlinear Mixed Effects Models. $R$ package version 3.1-122, http://CRAN.Rproject.org/package=nlme. 
Piscart, C., Navel, S., Maazouzi, C., Montuelle, B., Cornut, J., Mermillod-Blondin, F., Creuzé Des Châtelliers, M. C., Simon, L., Marmonier, P., 2011. Leaf litter recycling in benthic and hyporheic layers in agricultural streams with different types of land use. Sci. Total Environ., 409, 4373-4380.

Proia, L., Vilches, C., Boninneau, C., Kantiani, L., Farré, M., Romaní, A.M., Sabater, S., Guasch, H., 2013. Drought episode modulates the response of river biofilms to triclosan. Aquat. Toxicol., 127, 36-45.

Rasmussen, J.J., Wiberg-Larsen, P., Baattrup-Pedersen, A., Monberg, R.J., Kronvang, B., 2012a. Impacts of pesticides and natural stressors on leaf litter decomposition in agricultural streams. Sci. Total Environ., 416,148-155.

Rasmussen, J.J., Monberg, R.J., Baattrup-Pedersen, A., Cedergreen, N., Wiberg-Larsen, P., Strobel, B., Kronvang, B., 2012b. Effect of a triazole fungicide and a pyrethroid insecticide on the decomposition of leaves in the presence or absence of macroinvertebrate shredders. Aquat. Toxicol., 118, 54-61.

Richardson, S.D., Ternes, T.A., 2009. Water analysis: emerging contaminants and current issues. Anal. Chem., 81, 4645-4677.

Romaní, A.M., Fischer, H., Mille-Lindblom, C., Tranvik, L.J., 2006. Interactions of bacteria and fungi on decomposing litter: differential extracellular enzyme activities. Ecology, 87, 2559-2569.

Rong, Q., Sridhar, K.R., Bärlocher, F., 1995. Food selection of three leaf-shredding invertebrates. Hydrobiologia, 316, 173-181.

Schimel, J.P., Balser, T.C., Wallenstein, M., 2007. Microbial stress-response physiology and its implications for ecosystem function. Ecology, 88, 1386-1394.

Segner, H., Schmitt-Jansen, M., Sabater, S., 2014. Assessing the impact of multiple stressors on aquatic biota: the receptor's side matters. Environ. Sci. Technol., 48, 76907696.

Stampfli, N.C., Knillmann, S., Liess, M., Noskov, Y.A., Schäfer, R.B., Beketov, M.A., 2013. Two stressors and a community - Effects of hydrological disturbance and a toxicant on freshwater zooplankton. Aquat. Toxicol., 127, 9-20.

Stevenson, R.J., Sabater, S., 2010. Understanding effects of global change on river ecosystems: Science to support policy in a changing world. Hydrobiologia, 657, 3-18.

Suberkropp, K., Arsuffi, T.L., Anderson, J.P., 1983. Comparison of degradative ability, enzymatic activity, and palatability of aquatic hyphomycetes grown on leaf litter. Appl. Environ. Microbiol., 46, 237-244.

Swan, T.M., Watson, K., 1998. Stress tolerance in a yeast sterol auxotroph: role of ergosterol, heat shock proteins and trehalose. FEMS Microbiol. Lett., 169, 191-197.

Tlili, A., Maréchal, M., Bérard, A., Volat, B., Montuelle, B., 2011; Enhanced co-tolerance and co-sensitivity from long-term metal exposures of heterotrophic and autotrophic components of fluvial biofilms. Sci. Total Environ., 409, 4335-43.

Vinebrooke, R.D., Cottingham, K.L., Norberg, J., Scheffer, M., Dodson, S.I., Maberly, S.C., Sommer, U., 2004. Impacts of multiple stressors on biodiversity and ecosystem functioning: the role of species co-tolerance. Oikos, 104, 451-457.

Webster, J.R., Meyer, J.L., 1997. Organic matter budgets for streams: a synthesis. J. North Benthol. Soc., 16, 141-161. 
Yannarell, A.C., Busby, R.R., Denight, M.L., Gebhart, D.L., Taylor, S.J., 2011. Soil bacteria and fungi respond on different spatial scales to invasion by the legume Lespedeza cuneata. Frontiers in Microbiology 2.

Ylla, I., Sanpera-Calbet, I., Vázquez, E., Romaní, A.M., Muñoz, I., Butturini, A., Sabater, S., 2010. Organic matter availability during pre- and post-drought periods in a Mediterranean stream. Hydrobiologia 657, 217-232.

Zubrod, J.P., Bundschuh, M., Feckler, A., Englert, D., Schulz, R., 2011. Ecotoxicological impact of the fungicide tebuconazole on an aquatic decomposer-detritivore system. Environ. Toxicol. Chem., 30, 2718-2724.

Zubrod, J.P, Baudy, P., Schulz, R., Bundschuh, M., 2014. Effects of current-use fungicides and their mixtu.res on the feeding and survival of the key shredder Gammarus fossarum. Aquat. Toxicol., 150, 133-143.

Zubrod, J.P., Englert, D., Feckler, A., Koksharova, N., Konschak, M., Bundschuh, R., Schnetzer, N., Englert, K., Schulz, R., Bundschuh M., 2015. Does the current fungicide risk assessment provide sufficient protection for key drivers in aquatic ecosystem functioning? Environ. Sci. Technol., 49, 1173-1181.

Zubrod, J.P., Feckler, A., Englert, D., Koksharova, N., Rosenfeldt, R.R., Seitz, F., Schulz, R., Bundschuh, M., 2015b. Inorganic fungicides as routinely applied in organic and conventional agriculture can increase palatability but reduce microbial decomposition of leaf litter. J. Appl. Ecol., 52, 310-322. 


\section{Appendix A. Supplementary data}

The following are Supplementary data to this article:

Supplementary Figure 1. Mean bacterial biomass ( \pm s.e. ; $n=3$ ) on leaves collected in the four treatments (Ic, Itbz, Dc, Dtbz) at days 22 and 40.
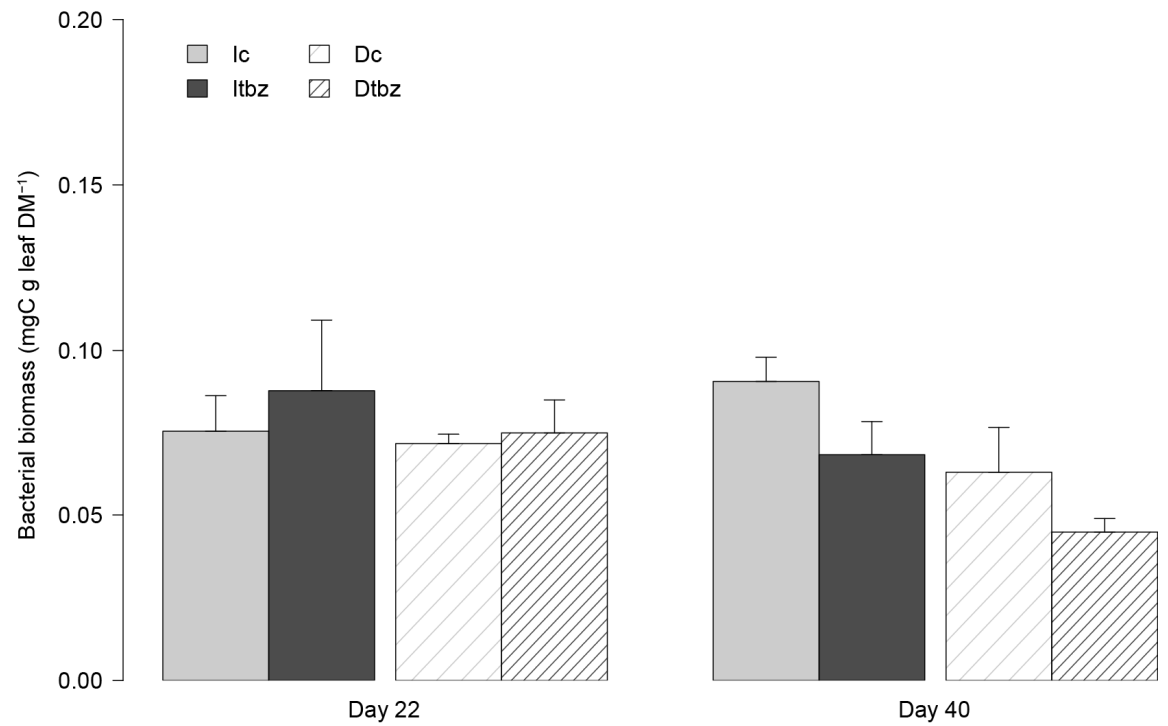

Day 40

Supplementary Figure 2. Mean concentrations of dissolved organic carbon ( \pm s.e. ; $n=3$ ) on leaves collected in the four treatments (Ic, Itbz, Dc, Dtbz) at days 22 and 40.

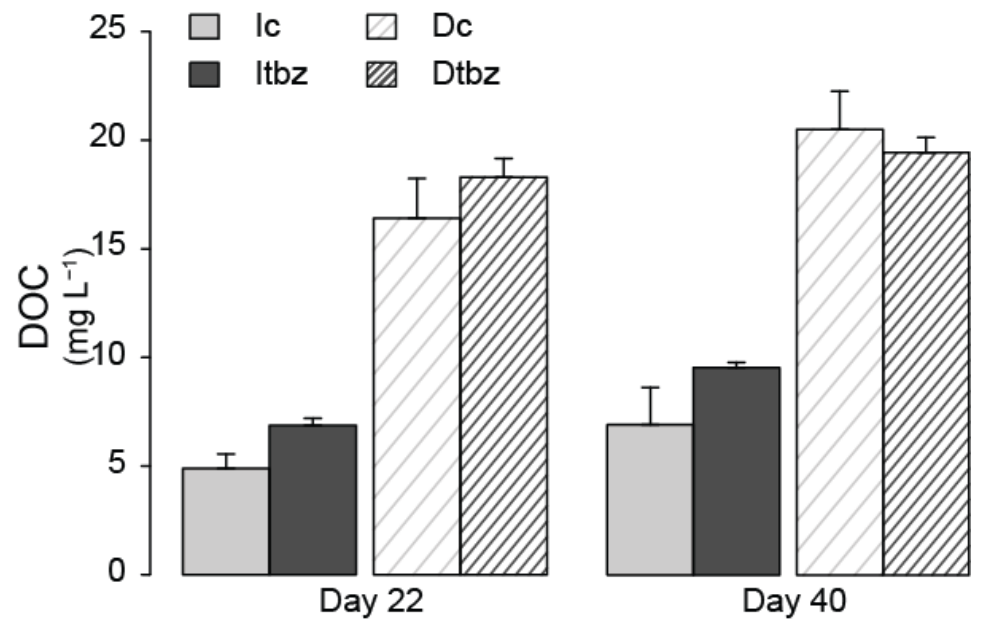

